\title{
The Role of Error Processing in the Contextual Interference Effect During the Training of Perceptual-Cognitive Skills
}

\author{
David P. Broadbent \\ Liverpool John Moores University and Brunel University
}

\author{
Joe Causer \\ Liverpool John Moores University \\ Paul R. Ford \\ University of Brighton
}

\begin{abstract}
The contextual interference (CI) effect refers to the learning benefits that occur from a random compared with blocked practice order. In this article, the cognitive effort explanation for the CI effect was examined by investigating the role of error processing. In 2 experiments, a perceptual-cognitive task was used in which participants anticipated 3 different tennis skills across a pretest, 3 practice sessions, and retention test. During practice, the skills were presented in either a random or blocked practice order. In Experiment 1, cognitive effort was examined using a probe reaction time (RT) task. In Experiment 2, cognitive effort was manipulated for 2 groups by inserting a cognitively demanding secondary task into the intertrial interval. The $\mathrm{CI}$ effect was found in both experiments as the random groups displayed superior learning in the retention test compared with the blocked groups. Cognitive effort during practice was greater in random compared to blocked practice groups in Experiment 1. In Experiment 2, greater decrements in secondary task performance following an error were reported for the random group when compared with the blocked group. The suggestion is that not only the frequent switching of tasks in randomized orders causes increased cognitive effort and the CI effect, but it is also error processing in combination with task switching. Findings extend the cognitive effort explanation for the CI effect and propose an alternative hypothesis highlighting the role of error processing.
\end{abstract}

Public Significance Statement

A random schedule (e.g., $\mathrm{CAB}$ ACB BAC) of practice has additional learning benefits compared with more traditional blocked practice (e.g., AAA BBB CCC). However, our conceptual understanding of this affect remains unclear. The findings indicated that the combination of switching between tasks during random practice and the processes associated with an error (e.g., comparing own response with the actual outcome and updating/correcting the rules for the upcoming trials) results in increased mental effort compared with blocked practice. This increase in mental effort underpins the learning benefits of random practice and emphasizes the importance of task switching and errors during practice. Practitioners, across various domains, interested in skill acquisition are encouraged to structure practice in a manner which avoids repetition and promotes task switching and errors.

Keywords: cognitive effort, anticipatory judgment, practice structure, perceptual learning, secondary task

The manner in which practice is structured affects skill acquisition. The contextual interference (CI) effect refers to the differential impact on skill acquisition of a random versus blocked

This article was published Online First March 16, 2017.

David P. Broadbent, Research Institute of Sport and Exercise Sciences, Liverpool John Moores University, and Division of Sport, Health and Exercise, Department of Life Sciences, Brunel University; Joe Causer, Research Institute of Sport and Exercise Sciences, Liverpool John Moores University; A. Mark Williams, Department of Health, Kinesiology, and Recreation, University of Utah; Paul R. Ford, Centre for Sport and Exercise Science and Medicine, University of Brighton.

Correspondence concerning this article should be addressed to David P. Broadbent, Division of Sport, Health and Exercise, Department of Life Sciences, Heinz Wolff Building (HNZW271), Brunel University, Uxbridge, London, UB8 3PH. E-mail: david.broadbent@brunel.ac.uk practice schedule. A random schedule, or high CI, involves switching between a number of tasks or actions during practice (e.g., CBA ACB BAC). In contrast, a blocked schedule of practice, or low CI, involves a number of tasks or actions being executed separately from one another in a repetitive manner (e.g., AAA BBB CCC). A random schedule of practice results in less improvement during practice, but promotes greater retention and transfer of skill, when compared to a blocked schedule of practice (Shea \& Morgan, 1979).

Although the CI effect is a robust finding, debate still remains around the underlying mechanisms of this phenomenon (Magill \& Hall, 1990). In the current article, the cognitive effort from task switching hypotheses for the CI effect is tested and an alternative hypothesis involving the processing of errors is examined. To our knowledge, the role of error processing and its effect on cognitive effort (Lam, Masters, \& Maxwell, 2010) has not previously been investigated in conjunction with the CI effect and could provide a 
novel explanation for the mechanisms underpinning this phenomenon. Moreover, little attention has been given to the effects of different practice schedules on the learning of anticipatory judgments (for an exception, see Broadbent, Causer, Ford, \& Williams, 2015). Much of the research surrounding the CI effect appears to predict that the planning, selection, and execution of motor skill is essential for the interference caused between tasks (Magill \& Hall, 1990). We examined the CI effect using a perceptual-cognitive task rather than the typical perceptual-motor task in order to provide a unique insight into the mechanisms underpinning this phenomenon (Memmert et al., 2009).

The CI effect is a robust finding for motor skill acquisition (for reviews, see Brady, 1998, 2008; Lee, 2012; Magill \& Hall, 1990; Merbah \& Meulemans, 2011; Wright et al., 2015). In the seminal article by Shea and Morgan (1979), participants performed three versions of a simple barrier knockdown motor task practiced in either a random or blocked order. During practice, the blocked order group demonstrated faster total movement times compared with the random order group. However, on the retention and transfer test, the random practice group had a faster total movement time compared to the blocked group, indicating superior learning. The CI effect has been shown in the acquisition of a wide variety of laboratory-based (Lee, Wulf, \& Schmidt, 1992; Magnuson \& Wright, 2004; Pauwels, Swinnen, \& Beets, 2014; Wright, Magnuson, \& Black, 2005), and applied motor tasks (Goode \& Magill, 1986; Hall, Domingues, \& Cavazos, 1994; Ollis, Button, \& Fairweather, 2005; Smith \& Davies, 1995).

Two theories have been proposed to explain the underlying mechanisms of the CI effect, namely the elaborative processing hypothesis and the action plan reconstruction hypothesis. Both theories detail how greater cognitive effort occurs during random compared with blocked ordered practice due to task switching (Lee, 2012). Cognitive effort is the mental work involved in selecting and executing decisions and actions (Lee, Swinnen, \& Serrien, 1994). According to the elaborative processing hypothesis, a random practice order leads to greater cognitive effort through intra- and intertask comparisons because the skills differ from trial to trial (Shea \& Titzer, 1993; Wright, 1991; Wright, Li, \& Whitacre, 1992). In comparison, during blocked practice the opportunity for contrasting the different actions is minimized to only intratask comparisons due to the repetitive nature of the practice order (Shea \& Zimny, 1983, 1988). Lin and colleagues (Lin, Fisher, Winstein, Wu, \& Gordon, 2008; Lin et al., 2009; Lin, Winstein, Fisher, \& Wu, 2010) investigated the CI effect using transcranial magnetic stimulation (TMS). In one study, novice participants practiced three different arm movement tasks in either a blocked or random practice structure. Single TMS pulses were synchronized to each intertrial interval to reduce information processing during the two practice conditions. The typical CI effect was found for groups without TMS. However, the random practice advantage was eliminated when TMS was applied between random practice trials, as it was suggested to prevent them from conducting elaborative processing (Lin et al., 2008).

According to the action plan reconstruction hypothesis, random practice requires more effortful processing because the action plan for the next trial has been forgotten and must be recalled. It is forgotten due to the interference of executing a different preceding action and must be retrieved from working memory for the next action. In comparison, blocked practice involves using the same action plan on each trial so no forgetting or retrieval/reconstruction processes occur (Lee \& Magill, 1983, 1985; Lee, Magill, \& Weeks, 1985). One method to examine this hypothesis has been to prevent the forgetting that is predicted to occur between trials in a random practice condition. For example, during the intertrial period participants observe a computer-generated demonstration of the movement pattern to be performed (Lee, Wishart, Cunningham, \& Carnahan, 1997). Observing a congruent demonstration in the intertrial period leads to similar performance from the random practice groups compared to blocked practice groups in both practice and retention tests, because it reduces forgetting and reconstructive processes. Cross, Schmitt, and Grafton (2007) used a key-press task to examine the neural substrates of the CI effect with functional MRI. Consistent with the reconstruction hypothesis, the random group showed greater activity in the planning regions of the brain, when compared with the blocked practice group.

Both the elaboration and action plan reconstruction hypotheses have led to the highly cited explanation that task switching causes the increased cognitive effort found during random practice (Li \& Wright, 2000). However, alternative explanations could provide a greater insight into the mechanisms involved. Researchers from the motor learning domain suggest that error processing increases cognitive effort through the demands associated with success or failure on a task (Holroyd, Yeung, Coles, \& Cohen, 2005; Koehn, Dickinson, \& Goodman, 2008). When errors occur, performers identify discrepancies between the actual outcome and the desired goal (Rabbitt, 1966, 1967). In addition, they generate rules, hypotheses and knowledge about future task requirements so as to improve subsequent performance (Maxwell, Masters, Kerr, \& Weedon, 2001). Therefore, an error trial leads to greater cognitive effort due to the additional processing that takes place when compared with an errorless trial (Lam et al., 2010). In the current article, we examine the proposal that it is not simply the switching of tasks that increases cognitive effort through elaborative and/or reconstructive processes, but that error processing also has an important role in this phenomenon by increasing the load in working memory during random practice when errors occur. This finding may link to findings that random practice causes an implicit mode of learning due an increased load in working memory (Rendell, Masters, Farrow, \& Morris, 2011).

The CI effect has recently been extended to perceptualcognitive skills training, offering a new domain through to which investigate the underlying mechanisms of this phenomenon (Broadbent, Causer, Ford, et al., 2015; Helsdingen, van Gog, \& van Merriënboer, 2011a, 2011b). The CI effect originated from a nonmotor task domain, the verbal learning literature, where Battig $(1972,1979)$ referred to it first as "intertask interference." The elaborative processing hypothesis is directly linked to this and other work on motor learning and, thus, support for this hypothesis would be expected in the perceptualcognitive skills domain (Broadbent, Causer, Ford, et al., 2015; Memmert et al., 2009). In contrast, the definition for the action plan reconstruction hypothesis states that for an upcoming task in random practice "a person must retrieve the appropriate motor program representing that action and then add the pa- 
rameters specific to the constraints and goal of the task to be performed" (Magill \& Hall, 1990, p. 271). Finding the CI effect in verbal or perceptual-cognitive tasks contradicts this definition of the action plan reconstruction hypothesis due to the absence of a physical action and an associated motor program. However, there is strong evidence to suggest that observing a movement can activate the brain via the mirror neuron system and excite the motor system through resonant mechanisms (e.g., Denis, Rowe, Williams, \& Milne, 2016; Kilner, Vargas, Duval, Blakemore, \& Sirigu, 2004). In previous research on the CI effect using a perceptual task with skilled participants (Broadbent, Causer, Ford, et al., 2015), the perceived action might have resonated within the individuals own motor system activating an action plan for completing the skill and enabling the individual to anticipate, rather than react to, the actions of others (Aglioti, Cesari, Romani, \& Urgesi, 2008). Alternatively, other researchers using nonmotor tasks (Carlson, Sullivan, \& Schneider, 1989; Carlson \& Yaure, 1988; Helsdingen et al., 2011a, 2011b) support the action plan reconstruction hypothesis explaining that random practice forces learners to discard the task "strategy" (Helsdingen et al., 2011a, 2011b) or "processing plan" (Carlson \& Yaure, 1988) between tasks and either retrieve or reconstruct a new strategy/plan for successive tasks. This notion indicates that the term action plan is not directly linked to a motor action plan, but rather suggests that for any task to be complete, be it motor or perceptual, a plan must be placed into working memory for the task to be carried out (Ericsson \& Kintsch, 1995). The disparity around the definition of the action plan reconstruction hypothesis is still yet to be fully acknowledged in the literature. The training of perceptual-cognitive skill offers a novel domain to directly examine whether elaborative and/or reconstructive processes take place during the CI effect and could allow for the proposal of new terminology and definitions to encompass both motor and perceptual tasks.

In this article, we provide insight into the well-established explanations for the CI effect, namely the elaborative processing hypothesis and the action plan reconstruction hypothesis, by investigating them in the novel domain of perceptual-cognitive skills training. Furthermore, an alternative hypothesis is examined to address whether the increased cognitive effort found for random practice is as a consequence of task switching in conjunction with error processing. Cognitive effort will be investigated across two experiments in which novice tennis players anticipate three different skills shown on life-sized video in either a random or blocked practice order. Anticipation performance will be recorded during a pretest, across three practice sessions, and on a retention test. It is expected that the $\mathrm{CI}$ effect will occur in both experiments with the blocked group outperforming the random group during practice, but in the retention test the random group will show superior learning compared to the blocked group. Furthermore, it is predicted that the random group will exhibit greater amounts of cognitive effort across practice compared with the blocked group, either supporting one or both of the action plan reconstruction hypothesis and the elaborative processing hypothesis from the CI literature. Moreover, cognitive effort is predicted to be greater during random practice on error trials, compared with blocked practice and errorless trials, as the combination between task switching and error processing increases the load in working memory.

\section{Experiment 1}

Cognitive effort is a flexible capacity that can be subdivided among tasks so long as the demands do not exceed the available capacity of attention (Kahneman, 1973). When a task demands a high level of cognitive effort, there is a smaller capacity left available to perform other tasks. Attentional capacity is often examined in both the CI and error literature using the dual- or secondary-task paradigm, which involves performance of two tasks simultaneously (Abernethy, Maxwell, Masters, van der Kamp, \& Jackson, 2007). Discrete secondary-tasks are often used, such as the probe RT (PRT), in which participants respond to an auditory tone while performing the primary task (Abernethy et al., 2007). The greater the cognitive demands of the primary task at any given moment, the slower the RT on the secondary task (Goh, Gordon, Sullivan, \& Winstein, 2014). PRT tasks have been used to examine the underlying mechanisms of the CI effect in motor skill tasks (Li \& Wright, 2000; Rendell et al., 2011), providing support for both the reconstructive and elaborative hypothesis. However, researchers are yet to examine these hypotheses for the acquisition of perceptualcognitive skills. PRT tasks have also been used to examine the effect of errors on cognitive effort (Lam et al., 2010), showing that cognitive effort is greater on trials involving an error when compared to errorless trials. No researchers to our knowledge have examined the effects of errors on cognitive effort as a function of the CI effect.

We examine the acquisition of anticipatory judgments under random or blocked practice conditions and the role of cognitive effort from task switching and error processing in the CI effect. Novice tennis players' anticipated three different tennis skills shown as life-sized videos in either random or blocked schedules across a pretest, three practice sessions, and a retention test. In accordance with the CI effect, it is expected that the blocked group will demonstrate superior response accuracy (RA) across practice compared to the random group, but in the retention test the random group will demonstrate superior RA compared with the blocked group (Shea \& Morgan, 1979). During practice, cognitive effort will be examined by inserting a PRT into two phases of a trial in accordance with the two hypotheses from the CI literature. First, the action plan reconstruction hypothesis predicts greater cognitive effort for the random group in the observation phase of a trial, when compared with the blocked group. This phase is when participants are told the requirements of the upcoming task and must retrieve and reconstruct an appropriate action plan (Li \& Wright, 2000). Second, the elaborative processing hypothesis predicts greater cognitive effort for the random group during the feedback phase of a trial. Feedback is gained on performance in this phase that is compared, through intra- and intertask comparisons, with previous successful and unsuccessful trials (Li \& Wright, 2000). During practice, cognitive effort and error processing will be analyzed using decision time (DT) from the secondary task in the observation and feedback phase, and from the primary task in the response phase (Lam et al., 2010). DT will be compared for a blocked and random schedule of practice following an error and an errorless trial. It is expected that following an error the random practice group will exhibit significantly greater cognitive effort in the observation, response, 
and feedback phase of a trial compared with the blocked group and errorless trials.

\section{Method}

Participants. Participants were 24 undergraduate students who were novice tennis players with no competition experience in the sport. They were randomly divided into either a blocked practice group ( $n=12$; four females and eight males; $M$ age $=$ 23.3 years, $S D=4.5)$ or a random practice group $(n=12$; four females and eight males; $M$ age $=23.5$ years, $S D=3.2$ ). No group differences were found for the primary anticipation task at pretest between the blocked $(M=52 \%, S D=4)$ and random groups $(M=48 \%, S D=9), p=.17, d=.60$. Informed consent was obtained from the participants prior to participation. The research was conducted in accordance with the ethical guidelines of the lead institution.

Task and apparatus. The task required participants to anticipate the landing location of tennis shots executed by a player on-screen. To create the video footage, three different intermediate level tennis players were filmed on a standard tennis court executing three shots: forehand groundstroke, forehand smash, and forehand volley (Broadbent, Causer, Ford, et al., 2015). The video was filmed from a camera placed on the center of the baseline of the tennis court at a height of $1.5 \mathrm{~m}$ to provide a representative view of the court from the participants' perspective. The footage was made into clips using video editing software (Adobe Premier CS5, San Jose, CA). Each video clip began with a black screen and the trial number, which appeared for $3 \mathrm{~s}$. Subsequently, the tennis film began, which consisted of the onscreen player standing at one of three central locations on the other side of the net, the ball arriving to the player, the player moving to the ball, and swinging the racket. Clips were occluded at ball-racket contact when the screen went black for $3 \mathrm{~s}$, before the next trial began. Shots landed in four locations on the participant's side of the court, which were occluded on the video: left short, right short, left deep, and right deep.

The experimental apparatus and setup is shown in Figure 1. Participants stood $4 \mathrm{~m}$ from the center of a $2.74 \times 3.66 \mathrm{~m}$ projection screen (Cinefold Projection Sheet, Draper Inc., Spiceland, IN) on which the test films were projected (Hitachi CP-X345, Yokohama, Japan). The size of the image approximated the lifesize proportions normally experienced in game situations when players are positioned on the baseline of the court. Participants wore a lapel microphone (Seinheisser EW 100 ENG G2 RF, Germany). They were required to respond quickly and accurately to the onscreen shot by verbally stating a number between 1 and 4 that corresponded to the area of the court where the ball could bounce $(1=$ left short; $2=$ right short; $3=$ left deep; $4=$ right deep). Participants did not perform a movement response as in previous research (Broadbent, Causer, Ford, et al., 2015), but stood still with a tennis racket in hand due to the movement restrictions caused by the secondary task. As stated previously, the action plan reconstruction hypothesis states that the motor program for an action must be retrieved and an action executed for interference to occur (e.g., Magill \& Hall, 1990). However, there is evidence to suggest that observing an action activates the individual's motor system enabling anticipatory behavior (e.g., Denis et al., 2016; Kilner et al., 2004). Therefore, it was predicted that a perceptual

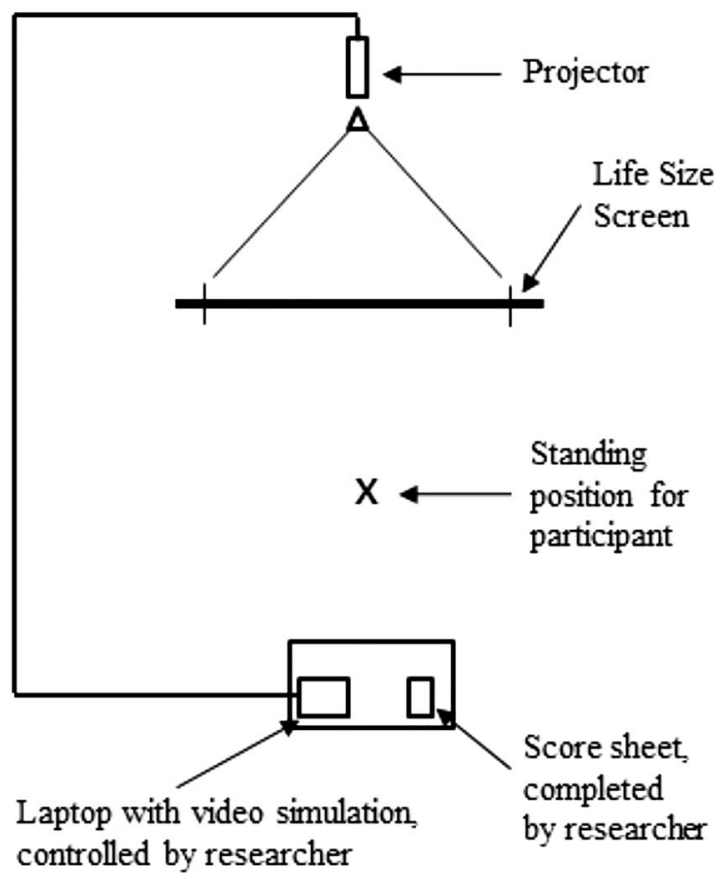

Figure 1. The experimental set up.

response would not cause differences in action planning compared to previous research using motor responses, as similar processing will occur due to resonant mechanisms in the brain (e.g., Aglioti et al., 2008).

A PRT secondary task was added to the clips shown during the practice phase. High $(2,500 \mathrm{~Hz})$ and low frequency $(300 \mathrm{~Hz})$ tones that were $240 \mathrm{~ms}$ in duration were overlaid on the clips using video editing software (Adobe Premier CS5, San Jose, CA). Probes were presented in a way that their onset could not be predicted through randomizing interstimulus intervals (Wulf, McNevin, \& Shea, 2001) and inserting catch trials in which a probe did not occur (Salmoni, Sullivan, \& Starkes, 1976). Participants were required to react to the PRT task on high, but not low, tones by pressing a button that was ergonomically attached to the tennis racket. The microphone and the button press were synchronized and analyzed with a developed algorithm through the computing environment MATLAB (Mathworks R2007, United Kingdom). This latter procedure allowed the verbal anticipation response by the participant, the onset of the high tones, and the moment the participant pressed the button on the racket to be recorded, providing DT data on each button press to a high tone. There were 54 high tones, 54 low tones, and 36 catch trials with two of these in each phase of each trial. The high tones were present on approximately $40 \%$ of trials. Additionally, a different tone was added at the beginning of each practice video, $2 \mathrm{~s}$ before the first trial began, which was used as a reference point for analyzing DT in the verbal responses.

Procedure. Participants took part in a pretest, three practice sessions, and a 10-min retention test. The pretest and practice blocks contained 36 trials each and the retention test consisted of 36 trials in a blocked order and 36 trials in random order 
counterbalanced across participants to ensure there was no bias toward either group (Broadbent, Causer, Ford, et al., 2015; Lin et al., 2008, 2009, 2010). Participants were informed of the response requirements for the films prior to testing. Pilot work ensured the clips were of similar difficulty and no clips were repeated across the different phases. The 36 trials in each phase comprised of 12 forehand groundstrokes, 12 forehand smashes, and 12 forehand volleys. Each set of 12 shot trials comprised of three trials to each of four locations on the court, which were occluded on the video: left short, right short, left deep, and right deep. The pretest trials were structured in a blocked order so that the three shots were in three separate sets each containing either forehand groundstrokes, smashes, or volleys together.

For the practice phase, three different films were constructed corresponding to each of the three practice sessions. For the blocked group, the clips were arranged in each session so that all groundstrokes were together, all smashes were together, and all volleys were together. For the random group, the clips were placed in a quasi-random order where none of the three shot-types was repeated more than twice in a row. Participants received two presentations of the same clip during each trial in the practice phase. The first video, termed the observation phase, contained clips that were temporally occluded at ball-racket contact and that occurred before the participant response. The second video, termed the feedback phase, occurred after their response and was not occluded, so that participants viewed the full clip and received feedback as to where the ball actually landed.

Participants were informed of the response requirements for the PRT task prior to practice. For each participant, the three practice sessions were split into one practice block with no tones, one block with tones across the first video (observation phase), and one block with tones across the second video (feedback phase). These prac- tice blocks were counterbalanced across participants (see Figure 2a). Participants also completed a PRT task alone prior to the experiment with no primary task so as to measure their base RT. Base level RT did not differ between the blocked group $(M=257$ $\mathrm{ms}, S D=61)$ and random group $(M=272 \mathrm{~ms}, S D=57), p=.54$, $d=.27$.

Data analysis. The dependent variables for the primary anticipation task were RA and DT. RA was expressed as the percentage of successful trials in which the response was the same as the location of the ball's landing on the court. DT (ms) was calculated as the difference between the time of the verbal response on each trial and the time of ball-racket contact or temporal occlusion. Responses initiated prior to ball-racket contact or occlusion received a negative value. RA and DT in the primary task were analyzed using a 2 Group (blocked, random) $\times 3$ Session (pretest, practice, retention) mixed-design ANOVA, with repeated measures on the last factor. For all ANOVAs partial-eta squared was calculated for effect size. Pairwise comparisons were used to follow-up any significant main effects. For significant interactions a planned comparison was used to address the specific a priori hypotheses on the retention test. For the planned comparison, Cohens $d$ was calculated for effect size.

The role of errors on cognitive effort as a function of blocked and random schedules of practice was examined using mean DT collapsed across all practice phases for the primary task. Analysis was conducted on the trial following an error as error processing occurs following feedback once the subject is aware of the error they have made and the nature of the error (Lam et al., 2010). The blocked group had approximately 58\% errorless trials and $42 \%$ errorful trials. The random group had approximately $50 \%$ errorless and errorful trials. A 2 Group $\times 2$ Error (errorless, error) mixed design ANOVA with repeated measure a

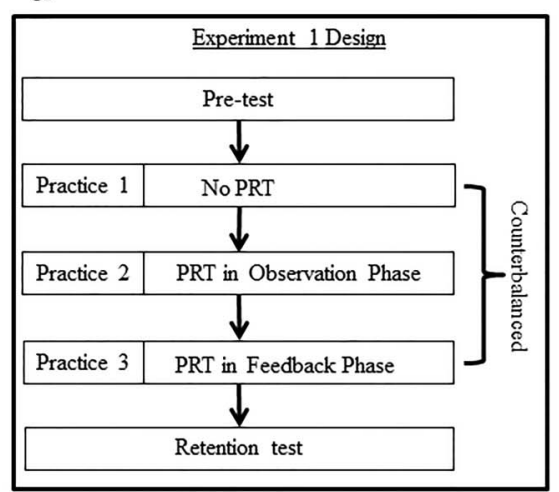

Experiment 1: Lavout of a trial

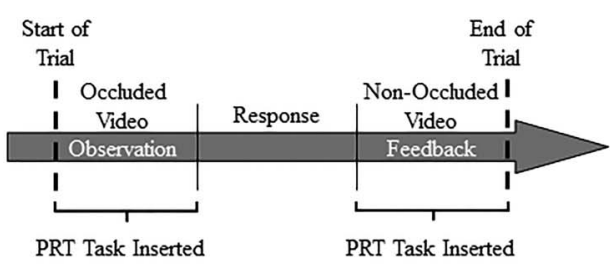

b

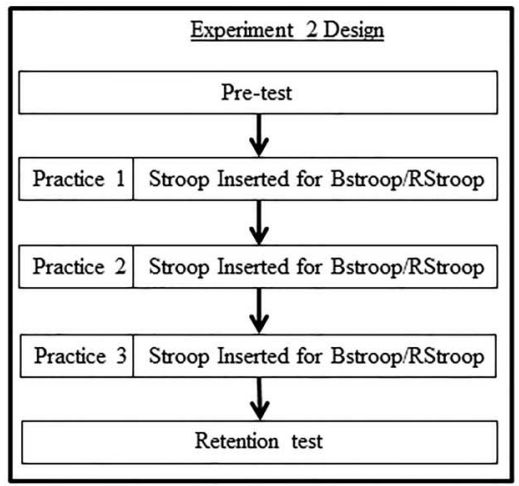

Experiment 2: Lavout of a Trial (RStroop/BStroop)

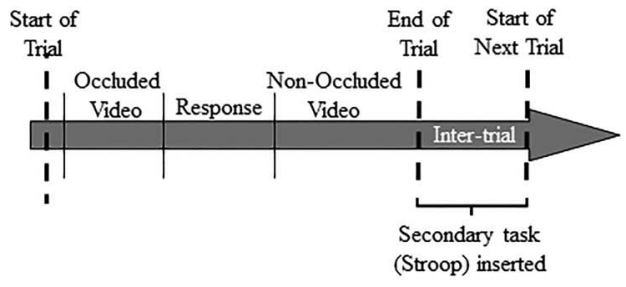

Figure 2. The experimental design and layout of an individual trial for (a) Experiment 1 and (b) Experiment 2. 
on the last factor was used to analyze DT in the primary anticipation task. Pairwise comparisons were used for any significant main effects. For any interactions, planned comparisons were used to address the specific a priori hypotheses. Updated alpha values are reported throughout.

The dependent variable for the secondary task was DT, which was calculated as the difference between the onset of the high tone on each trial and the button press by the participant. The role of errors was also analyzed for the secondary task in the observation and feedback phase separately. Secondary task DT was analyzed using a 2 Group $\times 2$ Phase (observation phase, feedback phase) $\times$ 2 Error (errorless, error) ANOVA, with repeated measures on the last factor. Pairwise comparisons were used for any significant main effects. For any interactions, planned comparisons were used to address the specific a priori hypotheses. In order to limit the potential inflation of Type-1 errors through multiple comparisons, each alpha level was adjusted using the Bonferroni correction method. Updated alpha values are reported throughout.

\section{Results}

\section{Primary anticipation task.}

Response accuracy. Figure 3 shows mean RA for the two groups in the pretest, during practice, and in the retention test. A 2 Group $\times 3$ Session ANOVA on RA revealed no group main effect, $F(1,22)=1.23, p=.28, \eta_{p}^{2}=.05$. There was a significant main effect for session, $F(2,44)=12.16, p<.01, \eta_{p}^{2}=.36$. RA in the pretest $(M=50 \%, S D=7)$ and practice $(M=54 \%, S D=$ 7) were significantly lower than in the retention tests $(M=58 \%$, $S D=7), p<.01$ and $p=.01$, respectively. There was a Group $\times$ Session interaction, $F(2,44)=9.94, p<.01, \eta_{p}^{2}=.31$. No differences were found for RA between the groups in the pretest as reported in the method section. Across practice the blocked group $(M=58 \%, S D=6)$ had significantly greater accuracy compared to the random group $(M=50 \%, S D=6), p<.01, d=1.33$. In the retention test, a planned comparison revealed that the random group $(M=61 \%, S D=6)$ demonstrated significantly greater

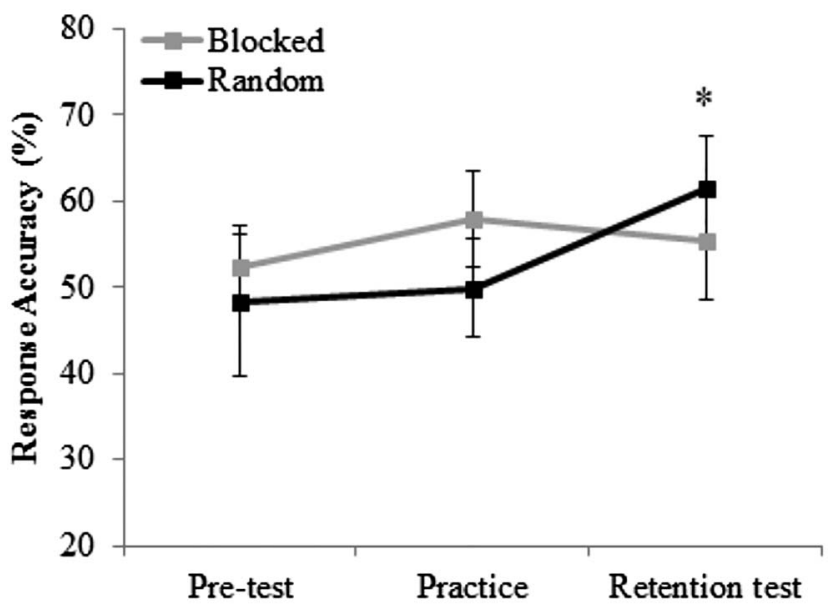

Figure 3. Experiment 1: Mean $(S D)$ response accuracy $(\%)$ in the primary anticipation task for the Blocked and Random group in the pretest, practice, and retention test. Error bars represent the standard deviation. ${ }^{*} p<.05$.
Table 1

Experiment 1: Mean (SD) Decision Time (ms) in the Primary Anticipation Task for the Blocked and Random Groups Across the Pretest, Practice, and Retention Test

\begin{tabular}{cccc}
\hline & \multicolumn{3}{c}{ Decision time $(\mathrm{ms})$} \\
\cline { 2 - 4 } Group & Pretest & Practice & Retention \\
\hline Blocked (SD) & $910(446)$ & $861(225)$ & $930(272)$ \\
Random (SD) & $952(591)$ & $893(186)$ & $790(150)$ \\
\hline
\end{tabular}

accuracy compared to the blocked group $(M=55 \%, S D=6), p=$ $.03, d=.92$.

Decision time. Table 1 shows mean DT in the primary task for the two groups across the pretest, practice, and retention test. A 2 Group $\times 3$ Session ANOVA on DT revealed no group main effect, $F(1,22)=.04, p=.85, \eta_{p}^{2}<.01$; session main effect, $F(2,44)=$ $.53, p=.59, \eta_{p}^{2}=.02$; or interaction, $F(2,44)=1.00, p=.36$, $\eta_{p}^{2}=.04$.

Error analysis. Table 2 shows the mean DT of the two groups on trials following error and errorless trials in the practice phase. A 2 Group $\times 2$ Error ANOVA on DT revealed no group main effect, $F(1,22)=.14, p=.71, \eta_{p}^{2}=.01$; error main effect, $F(1$, $22)=.58, p=.46, \eta_{p}^{2}=.03$; or interaction, $F(1,22)=3.10, p=$ $.09, \eta_{p}^{2}=.12$.

Secondary task.

Decision time. Figure 4 shows mean DT for the two groups on the PRT task across the observation and feedback phases during practice. In order to assess whether the secondary task had affected RA in the primary task, a one-way ANOVA on RA in the primary task between tone conditions was used. RA was not different between the tone only condition $(M=54 \%, S D=10)$, observation phase $(M=53 \%, S D=9)$, and the feedback phase $(M=55 \%$, $S D=6), F(2,46)=.48, p=.62, \eta_{p}^{2}=.02$, suggesting that the secondary task had not affected RA in the primary task, supporting previous research (Goh et al., 2014).

A 2 Group $\times 2$ Phase $\times 2$ Error ANOVA revealed a significant group main effect for DT, $F(1,22)=5.62, p=.03, \eta_{p}^{2}=.21$. The blocked group $(M=401 \mathrm{~ms}, S D=94)$ had a significantly faster DT compared with the random group $(M=507 \mathrm{~ms}, S D=136)$, $p=.03$. There was no main effect for phase, $F(1,22)=1.33, p=$ $.26, \eta_{\mathrm{p}}^{2}=.06$, and no Group $\times$ Phase interaction, $F(1,22)=.01$, $p=.99, \eta_{p}^{2}<.01$, indicating that the random group had a significantly slower DT across the observation and feedback phases during practice when compared to the blocked group.

Error analysis. Table 2 shows mean DT for the secondary task of the blocked and random groups as a function of performance success (errorless, error) in the previous trial. The 2 Group $\times 2$ Phase $\times 2$ Error ANOVA on DT revealed a significant Phase $\times$ Error interaction, $F(1,22)=5.28, p=.03, \eta_{p}^{2}=.19$. The planned comparison showed that differences in DT approached significance between an errorless trial in the feedback phase $(M=$ $476 \mathrm{~ms}, S D=154)$ and the observation phase $(M=425 \mathrm{~ms}, S D=$ 126), $p=.07, d=.36$, whereas there was no difference for error trials between the two phases $(p>.05)$. A follow up using Tukey's Honest Significance Test demonstrated the Phase $\times$ Error inter- 
Table 2

Experiment 1: Mean (SD) Decision Time (ms) in the Primary Anticipation Task, and Mean (SD)

Reaction Time (ms) in the Secondary Task, for the Blocked and Random Groups on Errorless and Error Responses in the Previous Trial

\begin{tabular}{|c|c|c|c|c|c|c|}
\hline \multirow[b]{3}{*}{ Group } & & & \multicolumn{4}{|c|}{ Probe reaction time $(\mathrm{ms})$} \\
\hline & \multicolumn{2}{|c|}{ Decision time (ms) } & \multicolumn{2}{|c|}{ Observation phase } & \multicolumn{2}{|c|}{ Feedback phase } \\
\hline & Errorless & Error & Errorless & Error & Errorless & Error \\
\hline Blocked $(S D)$ & $869(220)$ & $858(228)$ & $380(129)$ & $399(85)$ & $422(104)$ & $402(89)$ \\
\hline Random $(S D)$ & 880 (197) & $910(186)$ & 471 (109) & $521(147)$ & $530(180)$ & $505(172)$ \\
\hline
\end{tabular}

action was explained by this difference between the feedback and observation phase following errorless trials $(p=.04)$, as all other comparisons were not significantly different $(p>.05)$. No other interactions were significant, all $p>.05$.

\section{Discussion}

As predicted, in the primary anticipation task the traditional CI effect was found with the random practice group displaying superior response accuracy in the retention test compared with the blocked practice group (cf. Shea \& Morgan, 1979). Moreover, the random schedule of practice exhibited greater cognitive effort as shown by slower PRT compared with a blocked schedule of practice. Greater cognitive effort was found in both the observation and feedback phase of a trial for the random when compared with the blocked schedule of practice. Findings suggest that additional cognitive processes are used before, and after, an executed trial in a random compared to blocked schedule of practice, supporting the idea that both reconstructive and elaborative processes underpin the CI effect (Li \& Wright, 2000). With regards to the role of error processing in the CI effect, the data provided no support for this alternative hypothesis in either the observation or feedback phase. Findings suggest further research is required to either support or dispute this alternative hypothesis, perhaps by examining a different time-period during the practice trial such as the intertrial interval.

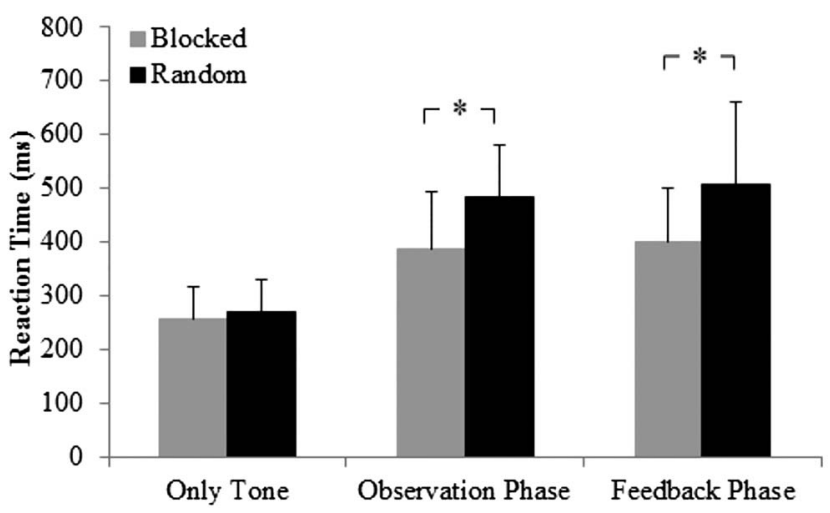

Figure 4. Experiment 1: Mean (SD) response time (ms) for the probe RT (PRT) for the Blocked and Random group in tone only, observation phase, and feedback phase. Error bars represent the standard deviation. ${ }^{*} p<.05$.

\section{Experiment 2}

Researchers investigating the underlying mechanisms of the CI effect have often referred to the intertrial interval as a critical time period when cognitive effort occurs (Magill \& Hall, 1990). The elaboration hypothesis predicts that inserting a cognitively demanding task during the intertrial interval will disrupt the elaborative processes taking place for a random schedule of practice and will diminish the superior learning of random practice (Lin et al., 2008; Lin et al., 2010). In contrast, the action plan reconstruction hypothesis predicts that a cognitively demanding task during the intertrial interval will promote forgetting in a blocked schedule of practice and inadvertently increase the reconstructive processes, resulting in increased learning for blocked practice (Lee \& Magill, 1983, 1985). In Experiment 1, evidence was not found for the hypothesis that error processing for a random schedule of practice may contribute to the greater cognitive effort compared to blocked schedule of practice. This hypothesis was investigated in the observation and feedback phase of a trial, but not in the intertrial interval.

In Experiment 2, we manipulate cognitive effort in the intertrial interval using a cognitively demanding task (Stroop test; MacLeod, 1991). Including a secondary task allows for the cognitive demands of the primary task to be analyzed. If the primary task is cognitively demanding, the inclusion of a demanding secondary task will exceed the available capacity of working memory and cause decrements in secondary task performance. In comparison, if the primary task is less cognitively demanding, then both tasks can be performed efficiently (Abernethy et al., 2007). Novice participants were divided into blocked, random, blocked-Stroop (BStroop), and random-Stroop (RStroop) groups. It is expected that the CI effect will occur in the primary anticipation task for the two groups without the Stroop test. With regards to the two practice groups with the Stroop test inserted in the intertrial interval, the elaborative processing hypothesis predicts that the RStroop group will have decrements in performance compared to the random group as the cognitively demanding task will interfere with the intratask comparisons made during a random schedule of practice (Lin et al., 2008; Lin et al., 2010). Alternatively, the action plan reconstruction hypothesis predicts that the BStroop group will demonstrate superior learning compared with the blocked group because the secondary task in the interval will cause short-term forgetting, promoting reconstructive activity for the BStroop group (Lee \& Magill, 1983, 1985; Simon \& Bjork, 2002). Moreover, with regards to error processing, in the intertrial interval the RStroop group are predicted to exhibit significantly greater cog- 
nitive effort following an error compared with an errorless trial. In contrast, the BStroop group is expected to show no differences in cognitive effort following an error and errorless trial due to the predicted lower amount of elaborative processing occurring in that practice structure.

\section{Method}

Participants. Participants were 56 undergraduate students who were novice tennis players with no competition experience in the sport. They were randomly divided into either a blocked group $(n=14 ; M$ age $=20.7$ years, $S D=1.6)$, random group $(n=14$; $M$ age $=20.9$ years, $S D=1.1)$, BStroop group $(n=14 ; M$ age $=$ 20.9 years, $S D=1.4)$, or RStroop group $(n=14 ; M$ age $=21.1$ years, $S D=1.1$ ). Each group had 11 males and three females. No group differences for response accuracy were found at pretest between the four groups, $p>.05$. Informed consent was obtained from the participants prior to participation. The research was conducted in accordance with the ethical guidelines of the lead institution.

Task and apparatus. The film clips and the protocol were the same as in Experiment 1 with a prepractice-retention design. No PRT measure was used in this experiment. For the BStroop and RStroop groups (see Figure 2b), a Stroop test was inserted in the intertrial interval of practice trials using video editing software (Adobe Premier CS5 software, San Jose, CA). The Stroop test was selected due to the high cognitive demands it places on working memory (Kane \& Engle, 2003; Long \& Prat, 2002). The Stroop test presents three color words, such as red, green, and blue, with a font color of text that is different to that of the word. On the video clips, a black screen appeared prior to the Stroop test on each trial that had either stated "color" or "word" in a large white font to inform participants of their response requirement. Participants were required to respond quickly and accurately by verbally stating either the word that was printed or the color that the word was printed in, as directed. Three words appeared consecutively following each trial of the primary task. Each word was presented on screen for $90 \mathrm{~ms}$ as pilot work demonstrated that this time allowed the task to be completed successfully, but was still challenging for the participants. The order of presentation was randomized so that participants were unaware of the response they had to provide prior to each of the 36 trials of the Stroop test. The randomized presentation requires a new action plan to be implemented into working memory on the subsequent trial, potentially causing more interference to the primary task (for a review of Stroop effect theory, see MacLeod, 1991, 1992).

Procedure. The experimental apparatus, set up, and procedure was the same as in Experiment 1 (see Figure 2b), although there was no PRT task, and the pretest contained a blocked $(n=18)$ and random $(n=18)$ structure of practice so as not to favor either group. In addition, the Stroop test occurred after every trial in all three practice sessions for those two groups. The lapel microphone was synchronized and analyzed with a developed algorithm through the numerical computing environment MATLAB (Mathworks R2007, United Kingdom). It allowed the verbal response by the participant on both the primary anticipation task and the Stroop test to be recorded and later analyzed.

Data analysis. For the primary anticipation task, the dependent variables were the same as in Experiment 1 and were ana- lyzed separately using three separate ANOVAs. To replicate the data analysis in Experiment 1, RA and DT in the primary task were analyzed using a 2 Group (blocked, random) $\times 3$ Session (pretest, practice, retention) mixed-design ANOVA, with repeated measures on the last factor. To analyze the additional groups, RA and DT in the primary task were analyzed using a 2 Group (blocked, BStroop) $\times 3$ Session (pretest, practice, retention) mixed-design ANOVA and a 2 Group (random, RStroop) $\times 3$ Session (pretest, practice, retention) mixed-design ANOVA. For all ANOVAs partial-eta squared was calculated for effect size. Pairwise comparisons were used to follow up any significant main effects. For significant interactions a planned comparison was used to address the specific a priori hypotheses on the retention test. For the planned comparison, Cohens $d$ was calculated for effect size.

Analysis of DT as a measure of cognitive effort on trials following errors was conducted for the primary anticipation task. DT was analyzed following an errorless and error response in the previous trial for the blocked and random groups. The percentages for errorless and errorful trials for each group were: blocked group (58\% errorless; $42 \%$ errorful trials), random group (50\% errorless; $50 \%$ errorful trials), BStroop group (52\% errorless; $48 \%$ errorful trials), RStroop group (52\% errorless; $48 \%$ errorful trials). To replicate the analysis in Experiment 1, a 2 Group (blocked, random) $\times 2$ Error mixed design ANOVA with repeated measure on the last factor was used to analyze DT in the primary anticipation task. To analyze the additional groups, DT was analyzed using a 2 Group (blocked, BStroop) $\times 2$ Error mixed-design ANOVA and a 2 Group (random, RStroop) $\times 2$ Error mixed-design ANOVA

For the Stroop test, the dependent variables were RA and DT. RA refers to the number of successful responses out of 108 trials and is defined as whether the color or word verbalized by the participant matched the trial requirements for the color or word displayed. DT (ms) was calculated as the difference between initiation of the verbal response on each Stroop trial and the moment the slide appeared on the screen. All responses were initiated after the slide appeared and received a positive value that was analyzed through MATLAB with the software extrapolating all the data points for the verbal responses. Separate 2 Group $\times 3$ Practice mixed design ANOVAs with repeated measures on the last factor were used to analyze RA and DT on the Stroop test. The role of errors was also analyzed for DT on the Stroop test using a 2 Group $\times 2$ Error mixed design ANOVA with repeated measure on the last factor. Pairwise comparisons were used to follow up any significant main effects. For significant interactions, planned comparisons were used to address any specific a priori hypotheses. Alpha level was adjusted using the Bonferroni correction method. Updated alpha values are reported throughout.

\section{Results}

Primary anticipation task.

Response accuracy. Figure 5 shows mean RA for the four groups on the pretest, three practice sessions, and the retention tests. A 2 Group (blocked, random) $\times 3$ Session ANOVA revealed no group main effect, $F(1,26)=.30, p=.59, \eta_{p}^{2}=.01$. There was a significant main effect for session, $F(2,52)=5.23, p=.01$, $\eta_{p}^{2}=.17$. RA in the retention test $(M=56 \%, S D=6)$ was significantly greater compared with the pretest $(M=51 \%, S D=$ $8), p=.02$, whereas RA in practice $(M=54 \%, S D=6)$ did not 


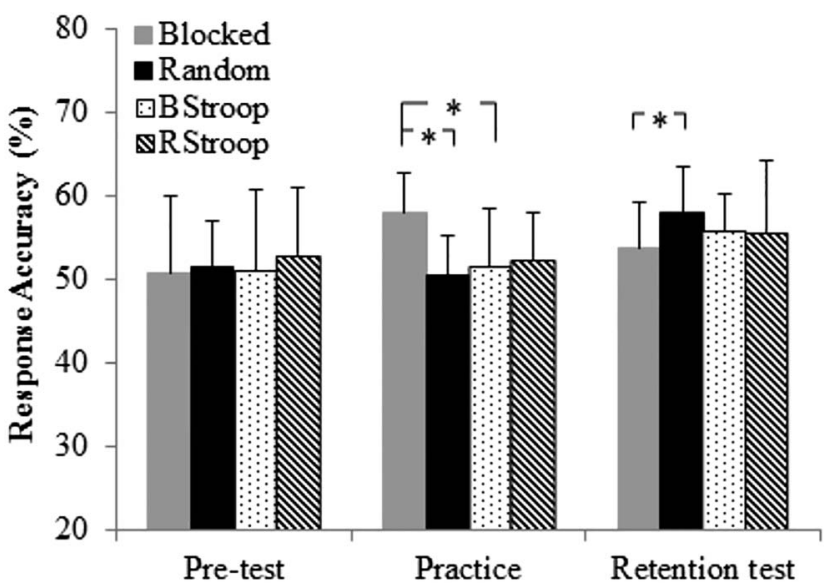

Figure 5. Experiment 2: Mean $(S D)$ response accuracy (number of correct trials) in the primary anticipation task for the Blocked, Random, BStroop, and RStroop groups in the pretest, practice, and retention test. Error bars represent the standard deviation. ${ }^{*} p<.05$.

differ to the pre- and retention test. There was a significant Group $\times$ Session interaction, $F(2,52)=8.47, p<.01, \eta_{p}^{2}=.25$. No between-groups differences were found in the pretest as shown in the methods section. Across practice the blocked group $(M=$ $58 \%, S D=5)$ were significantly more accurate than the random group $(M=50 \%, S D=5), p<.01, d=1.60$. In the retention test, the random group $(M=58 \%, S D=6)$ had significantly greater RA compared with the blocked group $(M=54 \%, S D=5), p=$ $.05, d=.77$.

A 2 Group (blocked, BStroop) $\times 3$ Session ANOVA revealed no group main effect, $F(1,26)=.43, p=.52, \eta_{p}^{2}=.02$. There was a significant main effect for session, $F(2,52)=4.94, p=.01$, $\eta_{p}^{2}=.16$. RA in the retention test $(M=55 \%, S D=5)$ was significantly greater compared with the pretest $(M=51 \%, S D=$ $9), p=.05$, whereas RA in practice $(M=54 \%, S D=7)$ did not differ to the pre- and retention test. There was a significant Group $\times$ Session interaction, $F(2,52)=4.95, p=.01, \eta_{p}^{2}=.16$. No between-groups differences were found in the pretest as shown in the methods section. The blocked group $(M=58 \%, S D=5)$ demonstrated superior RA across training compared to the BStroop group $(M=52 \%, S D=7), p=.01, d=1.07$, but there were no between-groups differences in RA in the retention test, $p=.27, d=.44$. The 2 Group (random, RStroop) $\times 3$ Session ANOVA revealed no group main effect, $F(1,26)=.03, p=.86$, $\eta_{p}^{2}<.01$. There was a significant main effect for session, $F(2$, $52)=8.25, p<.01, \eta_{p}^{2}=.24$. RA in the retention test $(M=57 \%$, $S D=7)$ was significantly greater compared to the pretest $(M=$ $52 \%, S D=7)$ and in practice $(M=51 \%, S D=5), p=.01$ and $p<.01$, respectively. There was no Group $\times$ Session interaction, $F(2,52)=1.30, p=.28, \eta_{p}^{2}=.05$.

Decision time. A 2 Group (blocked, random) $\times 3$ Session ANOVA revealed no group main effect, $F(1,26)=.69, p=.41$, $\eta_{p}^{2}=.03$. There was a significant main effect for session, $F(2$, $52)=5.01, p=.01, \eta_{p}^{2}=.16$. DT in the retention test $(M=890$ $\mathrm{ms}, S D=227)$ and in practice $(M=895 \mathrm{~ms}, S D=241)$ was significantly greater compared to the pretest $(M=805 \mathrm{~ms}, S D=$ $185), p=.03$ and $p=.01$, respectively. There was no Group $\times$ Session interaction, $F(2,52)=.56, p=.57, \eta_{p}^{2}=.02$.
A 2 Group (blocked, BStroop) $\times 3$ Session ANOVA revealed no group main effect, $F(1,26)=.07, p=.79, \eta_{p}^{2}<.01$. There was a significant main effect for session, $F(2,52)=6.96, p<.01$, $\eta_{p}^{2}=.21$. DT in practice $(M=870 \mathrm{~ms}, S D=226)$ was significantly greater compared to the pretest $(M=762 \mathrm{~ms}, S D=224)$, $p<.01$, whereas DT in the retention test $(M=832 \mathrm{~ms}, S D=237)$ did not differ to pretest and practice. There was no Group $\times$ Session interaction, $F(2,52)=.60, p=.55, \eta_{p}^{2}=.02$. The 2 Group (random, RStroop) $\times 3$ Session ANOVA revealed no group main effect, $F(1,26)=1.51, p=.23, \eta_{p}^{2}=.06$. There was no main effect for session, $F(2,52)=1.93, p=.16, \eta_{p}^{2}=.07$ and no Group $\times$ Session interaction, $F(2,52)=.12, p=.89, \eta_{p}^{2}=.01$.

Error analysis. Figure 6 shows mean DT in the primary task following an errorless or error response across the practice phase for the four groups. A 2 Group (blocked, random) $\times 2$ Error mixed design ANOVA revealed no group main effect, $F(1,26)=.06, p=$ $.80, \eta_{p}^{2}<.01$ and no error main effect, $F(1,26)=3.34, p=.08, \eta_{p}^{2}=$ .11. However, there was a significant Group $\times$ Error interaction, $F(1$, 26) $=8.32, p=.01, \eta_{p}^{2}=.24$. The random practice group had significantly slower DT following an error $(M=930 \mathrm{~ms}, S D=225)$ compared with following an errorless trial $(M=893 \mathrm{~ms}, S D=217)$, $p=.02, d=0.81$. In contrast, the blocked group showed no difference in DT following an error $(M=883 \mathrm{~ms}, S D=269)$ compared with following an errorless trial $(M=892 \mathrm{~ms}, S D=268)$, $p=1.00, d=0.22$.

A 2 Group (blocked, BStroop) $\times 2$ Error mixed design ANOVA revealed no group main effect, $F(1,26)=.10, p=.75, \eta_{p}^{2}<.01$. There was a significant main effect of error, $F(1,26)=6.46, p=.02$, $\eta_{p}^{2}=.20$. DT was significantly slower following an errorless trial $(M=882 \mathrm{~ms}, S D=225)$ compared with an error $(M=865 \mathrm{~ms}$, $S D=229), p=.02$. There was no Group $\times$ Error interaction, $F(1$, 26) $=1.66, p=.21, \eta_{p}^{2}=.06$. A 2 Group (random, RStroop) $\times 2$ Error mixed design ANOVA revealed no group main effect, $F(1$, 26) $=.79, p=.38, \eta_{p}^{2}=.03$. There was a significant main effect of error, $F(1,26)=4.61, p=.04, \eta_{p}^{2}=.15$. DT was significantly slower following an error $(M=885 \mathrm{~ms}, S D=212)$ compared with an errorless trial $(M=867 \mathrm{~ms}, S D=201), p=.04$. There was also a significant Group $\times$ Error interaction, $F(1,26)=5.26, p=.03, \eta_{p}^{2}=$ .17. The random practice group had significantly slower DT following error compared with errorless trials, whereas the RStroop group showed no significant difference in DT following an error $(M=841$

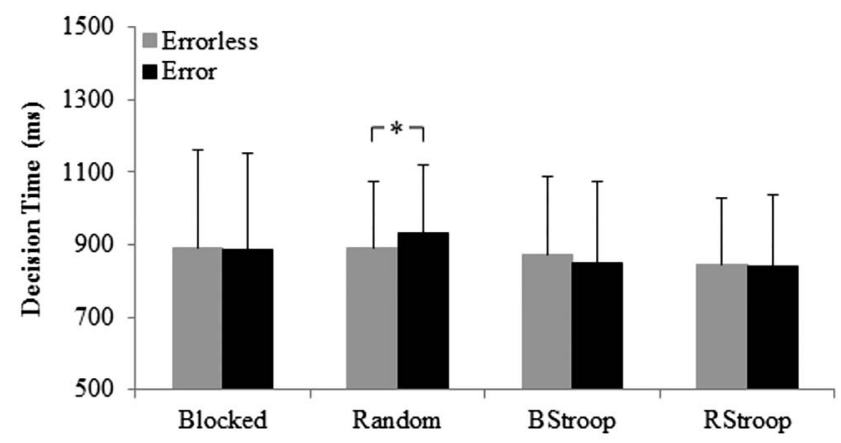

Figure 6. Experiment 2: Mean $(S D)$ decision time $(\mathrm{ms})$ in the primary anticipation task for the Blocked, BStroop, Random group and RStroop groups following error and errorless trials. Error bars represent the standard deviation. ${ }^{*} p<.05$. 
$\mathrm{ms}, S D=195)$ compared with an errorless trial $(M=843 \mathrm{~ms}, S D=$ 188), $p=1.00, d=0.01$.

\section{Stroop test.}

Response accuracy. Table 3 shows the mean RA on the Stroop test for the BStroop and RStroop groups across the three practice sessions. A 2 Group $\times 3$ Practice ANOVA revealed no group main effect, $F(1,26)=1.23, p=.28, \eta_{p}^{2}=.05$. There was a practice main effect, $F(2,52)=4.48, p=.02, \eta_{p}^{2}=.15$. RA in Practice $3(M=105$, $S D=4)$ was significantly greater than in Practice $1(M=104, S D=$ $4), p=.02$, whereas RA in Practice $2(M=105 \mathrm{~ms}, S D=3)$ did not differ to pretest and practice. No Group $\times$ Practice interaction occurred, $F(2,52)=.60, p=.55, \eta_{p}^{2}=.02$.

Decision time. Table 3 shows the mean DT in the Stroop test for the BStroop and RStroop groups across the three practice sessions. A 2 Group $\times 3$ Practice ANOVA revealed no group main effect, $F(1,26)=.014, p=.91, \eta_{p}^{2}<.01$, no main effect for practice, $F(2,52)=1.30, p=.28, \eta_{\mathrm{p}}^{2}=.05$, and no Group $\times$ Practice interaction, $F(2,52)=.01, p=.99, \eta_{p}^{2}<.01$.

Error analysis. Figure 7 shows mean DT for the BStroop and RStroop group in the secondary Stroop task following an error and an errorless trial across practice. A 2 Group $\times 2$ Error ANOVA revealed no group main effect, $F(1,26)=.01, p=.91, \eta_{p}^{2}<.01$. There was a significant error main effect, $F(1,26)=12.16, p<$ $.01, \eta_{p}^{2}=.32$. DT was significantly slower following an error $(M=681 \mathrm{~ms}, S D=87)$ compared to following an errorless trial $(M=664 \mathrm{~ms}, S D=85), p<.01$. There was also a significant Group $\times$ Error interaction, $F(1,26)=4.25, p=.05, \eta_{p}^{2}=.14$. DT for the RStroop was significantly slower following an error $(M=$ $687 \mathrm{~ms}, S D=85)$ compared to an errorless trial $(M=661 \mathrm{~ms}$, $S D=81), p<.01, d=1.68$. In comparison, DT for the BStroop group was not different following error $(M=674 \mathrm{~ms}, S D=91)$ and errorless trials $(M=667 \mathrm{~ms}, S D=91), p=.88, d=.21$.

\section{Discussion}

As expected, for the two practice structure groups without the secondary task the traditional CI effect was found (Shea \& Morgan, 1979). In the retention test, the random group was significantly more accurate compared to the blocked group, whereas in the pretest there was no between-groups difference in accuracy. With regards to the performance in the primary anticipation task for the two groups with the secondary Stroop test, no support was provided for either the elaboration hypothesis or the action plan reconstruction hypothesis. RA for the RStroop group in the retention test was not significantly different to the random group,

Table 3

Experiment 2: Mean (SD) Response Accuracy (Number of Correct Trials) and Decision Time (ms) in the Stroop Test for the BStroop and RStroop Groups Across the Three Practice Sessions

\begin{tabular}{|c|c|c|c|c|c|c|}
\hline \multirow[b]{2}{*}{ Group } & \multicolumn{2}{|c|}{ Practice 1} & \multicolumn{2}{|c|}{ Practice 2} & \multicolumn{2}{|c|}{ Practice 3} \\
\hline & $\mathrm{RA}(n)$ & DT (ms) & $\mathrm{RA}(n)$ & DT (ms) & $\mathrm{RA}(n)$ & DT (ms) \\
\hline $\begin{array}{l}\text { BStroop } \\
\quad(S D)\end{array}$ & $104(4)$ & $691(71)$ & 105 (4) & $668(100)$ & $104(4)$ & $662(120)$ \\
\hline $\begin{array}{l}\text { RStroop } \\
\quad(S D)\end{array}$ & $104(4)$ & $685(74)$ & $106(3)$ & 664 (98) & $106(3)$ & $661(126)$ \\
\hline
\end{tabular}

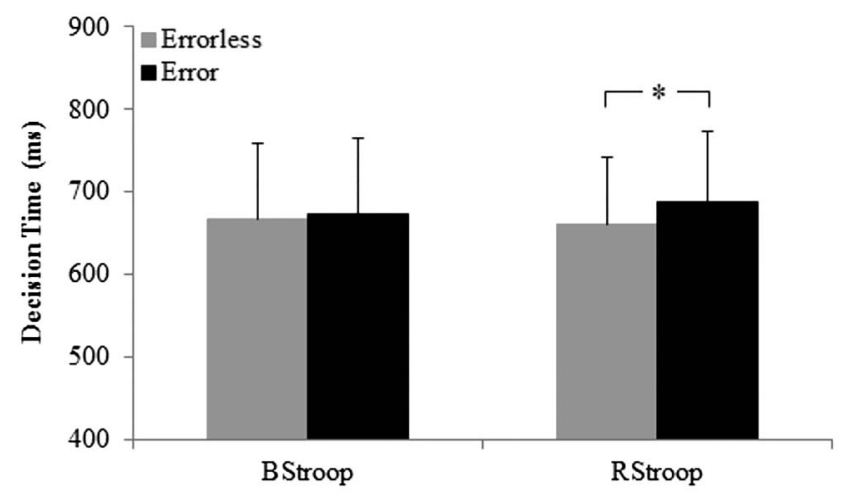

Figure 7. Experiment 2: Mean (SD) decision time (ms) in the secondary Stroop task for the BStroop and RStroop groups following error and errorless trials. Error bars represent the standard deviation. ${ }^{*} p<.05$.

suggesting that the participants were able to cope with the additional cognitive effort caused by the secondary task or they prioritized effort to maintain performance on the primary task at the cost of secondary task performance (Abernethy et al., 2007). Moreover, while the BStroop group were descriptively more accurate than the blocked group in the retention test as predicted and a significant interaction was found, the planned comparison did not reach significance. The suggestion is that the task did not cause a sufficient amount of forgetting, retrieval, and reconstructive processes during practice compared to methods used in previous studies (Lin et al., 2008, 2010).

DT in the primary anticipation task was slower following an error compared with an errorless trial for the random group, but not for the other three groups. This finding suggests that following an error, greater cognitive effort is required using a random schedule of practice to generate an appropriate response compared to a blocked schedule of practice (Lam et al., 2010). However, contrary to predictions, DT in the primary anticipation task was not different between errorless and error responses for the RStroop group, suggesting that the secondary task affected the cognitive processes taking place. Performance on the Stroop task allowed for more of an insight into the effect of error processing on working memory for the RStroop and BStroop groups. The RStroop group had a slower RT in the Stroop test following an error compared with following an errorless trial. In comparison, RT for the BStroop group was not different following both errorless and error trials. It appears that performance decrements occurred on the secondary task for the RStroop group in order to maintain performance in the primary task. In contrast, the BStroop group could maintain performance in both the primary and secondary task due to lower cognitive demands of the primary task. The data show that this performance decrement in the secondary task for the RStroop group was not across every trial, but rather only following an error. This finding provides support for the alternative hypothesis that it is not just task switching that increases the load in working memory for the random group, but a combination of task switching in conjunction with error processing.

\section{General Discussion}

In this article, we presented two experiments that examined the cognitive processes underlying the CI effect during the learning of 
anticipation judgments in tennis, specifically examining the role of error processing. In Experiment 1, we used a PRT task to measure cognitive effort in the observation and feedback phase of a trial during blocked and random practice. Cognitive effort was examined following errorless and error trials for blocked and random practice orders. In Experiment 2, we investigated the effects of inserting a cognitively demanding secondary task into the intertrial interval of blocked and random practice, while again investigating the effects of errors on performance of the primary and secondary task.

\section{Contextual Interference Effect and the Underlying Mechanisms}

As predicted, in both experiments the anticipation accuracy of the random practice group was not different in the pretest but significantly more accurate in the retention test when compared with the blocked group. Our findings support previous research on the CI effect in the motor skills literature (Shea \& Morgan, 1979) and provide confirmation that the effect extends to perceptualcognitive skills training (Broadbent, Causer, Ford, et al., 2015; Memmert et al., 2009). The data demonstrate the generalizability of the CI effect to perceptual-cognitive as well as perceptual-motor skills training, as the phenomenon has now been found to extend to skilled (Broadbent, Causer, Ford, et al., 2015) and novice participants using both complex movement responses (Broadbent, Causer, Ford, et al., 2015) and no movement responses. These findings indicate that a motor response may not be necessary to induce a CI effect; rather it is the cognitive processes that are key (Battig, 1972; Blandin, Proteau, \& Alain, 1994). For decision time in the primary task, no differences were found between the two groups in any phase, contrary to previous research by Broadbent, Causer, Ford, et al. (2015). This contradictory finding is potentially due to the different tasks used in the two papers. Broadbent, Causer, Ford, et al. (2015) used a field-based transfer test with no temporal occlusion paradigm. In the current study, a laboratorybased setting was used and the footage was occluded around ball-racket contact. The temporal occlusion paradigm forces participants to respond to the footage earlier than they usually would, so a floor effect is found for the decision time data (Broadbent, Causer, Williams, \& Ford, 2015).

The two experiments examined the underlying cognitive mechanisms of the CI effect using the novel domain of perceptualcognitive skills training. The majority of previous research has examined the CI effect using a motor task and debate still remains around the underlying mechanisms of this phenomenon. To provide further insight into the mechanisms involved, different secondary task protocols were used in the two experiments. These protocols enabled investigation of the cognitive effort involved at specific time points across an anticipation trial, examining both the elaborative processing hypothesis and the action plan reconstruction hypothesis (Magill \& Hall, 1990).

Elaborative processing hypothesis. Support for the elaborative processing hypothesis was expected in a perceptual-cognitive skills task as the early work on the CI effect used a nonmotor skill task to propose that intertask comparisons were the source of interference in random practice (Battig, 1972, 1979). In Experiment 1 , we showed that cognitive effort was greater in the feedback phase of a trial for a random compared to blocked schedule of practice. The feedback phase has previously been linked to the elaborative processing hypothesis as comparisons between trials can only occur once the participant is aware of the outcome of the trial (Li \& Wright, 2000). This finding supports the elaborative processing hypothesis as the increased cognitive effort of the random group indicates that intertask comparisons occurred in this practice condition but not in the blocked group (Shea \& Zimny, 1983, 1988). However, the findings reported in Experiment 2 did not support the elaborative processing hypothesis. Inserting a cognitively demanding secondary task into the intertrial interval did not affect learning in a random structure of practice, thereby contradicting previous research that has shown this effect (Lin et al., 2008). However, previously, researchers did not use a secondary task, but rather used TMS to disrupt elaborative processes (Lin et al., 2008; Lin et al., 2010). It may have been that the Stroop task was not disruptive enough to interfere with the between task comparisons taking place.

Action plan reconstruction hypothesis. While the elaborative processing hypothesis provides a plausible explanation for the acquisition of perceptual-cognitive skills, the action plan reconstruction hypothesis seems more precariously linked to this domain due to the idea that a motor program must be present in this process (Magill \& Hall, 1990). The current data provided mixed support for this hypothesis. Experiment 2 provided only tentative evidence for the action plan reconstruction hypothesis. While the BStroop group did increase response accuracy in the retention test compared with the blocked group, this change did not reach conventional levels of significance. The suggestion is that the Stroop test may not have been as cognitively demanding as task switching and did not cause total forgetting of an action plan (Lee \& Magill, 1983, 1985; Simon \& Bjork, 2002). Alternatively, the Stroop task may have been too similar to the primary task, as both were perceptual in nature, and between-task similarity is negatively related to the CI effect (Boutin \& Blandin, 2010).

In contrast, evidence from Experiment 1 supported the action plan reconstruction hypothesis and contradicts the notion that this hypothesis only applies to motor tasks (Broadbent, Causer, Ford, et al., 2015; Carlson et al., 1989; Carlson \& Yaure, 1988; Helsdingen et al., 2011a, 2011b). Greater cognitive effort was found in the observation phase of the trial for random compared to blocked practice. The observation phase has been linked to the action plan reconstruction hypothesis because an action plan can only be retrieved and reconstructed once participants are aware of the requirements of the upcoming task (Li \& Wright, 2000). There are a few plausible explanations as to why the action plan reconstruction hypothesis is still applicable to a nonmotor task. The evidence concerning action anticipation suggests that the motor system becomes activated through resonant mechanisms when observing an action (e.g., Aglioti et al., 2008). Therefore an action plan, as understood in the CI literature, is still implemented for the observed action. However, the current experiment used novice tennis player without a fine-tuned motor resonance system for the observed task, which suggests that this is not a fully valid argument (Broadbent, Causer, Ford, et al., 2015). Alternatively, it may be that the definition and terminology currently used needs to be adjusted to acknowledge nonmotor tasks. Previously, researchers have suggested that "strategies" and "processing plans" will still need to be retrieved and reconstructed similar to a motor program (Carlson \& Yaure, 1988; Helsdingen et al., 2011a, 2011b). We propose that to provide an 
explanation consistent for both motor and nonmotor tasks the terminology should be changed from the action plan reconstruction hypothesis to the response plan reconstruction hypothesis. As such, the definition for this hypothesis must state that for an upcoming task a person must retrieve and reformulate the appropriate response plan on each attempt as it has been forgotten by intervening responses. The individual under a random schedule of practice engages in more effortful reconstructive process to regenerate the response plan for subsequent performances.

Overall the current data showed some evidence for both the elaborative processing and action plan reconstruction hypothesis (Magill \& Hall, 1990). Data from Experiment 1 indicate that elaborative and reconstructive processes occur in the observation and feedback phase, respectively. This finding suggests that the two hypotheses might not be viewed as being separate, but rather as an integrated hypothesis involving greater cognitive effort across the whole of the trial. In contrast, data from Experiment 2 examining the hypothesis led to null effects, suggesting an alternative hypothesis may have to be considered to explain this phenomenon.

\section{Alternative Hypothesis: Error Processing}

We investigated error processing as an additional explanation for the increased cognitive effort underlying random practice. Previously, researchers have suggested it is the switching of tasks that increases the load in working memory and underlies the learning benefits of random compared with blocked practice (Rendell et al., 2011). The current data provided some support for the proposal that task switching in conjunction with error processing underpins the CI effect. In Experiment 2, we demonstrated that RStroop group performance on the secondary task was negatively affected following an error compared with an errorless trial, supporting the error-processing hypothesis. Participants allocated more resources to the primary task on these trials to process errors in addition to the elaborative processing and response plan reconstruction caused by task switching. This finding shows some support for the idea that random practice increases the load in working memory similar to a secondary task and may create a form of implicit learning (Rendell et al., 2011). Moreover, in Experiment 2, support for the error-processing hypothesis was shown as the random group demonstrated slower decision times on the primary task following an error compared with an errorless trial, suggesting that the monitoring and controlling of a response increases following an error for the random, but not the blocked, practice group (Holroyd et al., 2005; Lam et al., 2010).

An alternative hypothesis is outlined combining ideas and concepts from the CI literature (Magill \& Hall, 1990) and the error processing literature (Lam et al., 2010). The hypothesis suggests that error processing in conjunction with task switching may underpin the increased cognitive effort found for a random compared to blocked structure of practice. The greater cognitive effort following an error for a random schedule of practice could be due to participants having to both update the current rules for the previous task and store these (error processing), as well as retrieving the response plan for the upcoming task (reconstructive processes). The updating of responses would occur through inter- and intratask comparisons (elaborative processing) made to identify discrepancies between the actual outcome and the desired goal (error processing). In contrast, following an error, a blocked struc- ture of practice would not require the retrieval of a response plan (reconstructive processes) due to the repetitive nature of the trials, so would merely require the rules for the task to be updated (error processing) and this would not involve intertask comparisons (elaborative processes), hence less cognitive effort would be required. This hypothesis is made tentatively and is to allow for clear hypotheses to be tested in future research to either support or contradict the potential role of error processing in the CI effect.

\section{Conclusions}

In this article, we report two experiments that provided confirmation of the CI effect for the acquisition of perceptual-cognitive skills and some support for both the elaborative processing hypothesis and the newly termed response plan reconstruction hypothesis. Moreover, the experiments provide a novel insight into the role of error processing as a potential underlying mechanism in the CI effect. The current literature suggests that cognitive effort is greater for random practice compared with blocked practice due to task switching, specifically through elaborative and reconstructive processes. However, the current data further suggests that it may not be solely the switching of the tasks that underpins the CI effect, but error processing in conjunction with the task switching that causes greater cognitive effort for a random schedule of practice. In future, researchers should seek to examine error processing as an additional underlying mechanism of the CI effect. Furthermore, the extent to which task switching and error processing increase the load in working memory and potentially create a type of implicit learning should be examined (Rendell et al., 2011). The CI effect has been shown to extend to a range of domains and conditions from simple motor skill tasks with novice participants (e.g., Shea \& Morgan, 1979) to complex sporting tasks with expert athletes (e.g., Hall, Domingues, \& Cavazos, 1994). Further research is required to assess the role of error processing in conjunction with task switching in a variety of domains and conditions to determine the generalizability of the alternative theory proposed in this article.

\section{References}

Abernethy, B., Maxwell, J. P., Masters, R. S., van der Kamp, J., \& Jackson, R. C. (2007). Attentional processes in skill learning and expert performance. In G. Tenenbaum \& R. C. Eklund (Eds.), Handbook of sport psychology (pp. 245-263). Hoboken, NJ: Wiley http://dx.doi.org/10 1002/9781118270011.ch11

Aglioti, S. M., Cesari, P., Romani, M., \& Urgesi, C. (2008). Action anticipation and motor resonance in elite basketball players. Nature Neuroscience, 11, 1109-1116. http://dx.doi.org/10.1038/nn.2182

Battig, W. F. (1972). Intratask interference as a source of facilitation in transfer and retention. In R. F. Thompson \& J. F. Voss (Eds.), Topics in learning and performance. New York, NY: Academic Press.

Battig, W. F. (1979). The flexibility of human memory. In L. S. Cermak \& F. I. M. Craik (Eds.), Levels of processing in human memory (pp. 23-44). Hillsdale, NJ: Erlbaum.

Blandin, Y., Proteau, L., \& Alain, C. (1994). On the cognitive processes underlying contextual interference and observational learning. Journal of Motor Behavior, 26, 18-26. http://dx.doi.org/10.1080/00222895.1994 .9941657

Boutin, A., \& Blandin, Y. (2010). Cognitive underpinnings of contextual interference during motor learning. Acta Psychologica, 135, 233-239. 
Brady, F. (1998). A theoretical and empirical review of the contextual interference effect and the learning of motor skills. Quest, 50, 266-293. http://dx.doi.org/10.1080/00336297.1998.10484285

Brady, F. (2008). The contextual interference effect and sport skills. Perceptual and Motor Skills, 106, 461-472. http://dx.doi.org/10.2466/ pms.106.2.461-472

Broadbent, D. P., Causer, J., Ford, P. R., \& Williams, A. M. (2015). Contextual interference effect on perceptual-cognitive skills training. Medicine and Science in Sports and Exercise, 47, 1243-1250. http://dx .doi.org/10.1249/MSS.0000000000000530

Broadbent, D. P., Causer, J., Williams, A. M., \& Ford, P. R. (2015). Perceptual-cognitive skill training and its transfer to expert performance in the field: Future research directions. European Journal of Sport Science, 15, 322-331. http://dx.doi.org/10.1080/17461391.2014.957727

Carlson, R. A., Sullivan, M. A., \& Schneider, W. (1989). Practice and working memory effects in building procedural skill. Journal of Experimental Psychology: Learning, Memory, and Cognition, 15, 517-526. http://dx.doi.org/10.1037/0278-7393.15.3.517

Carlson, R. A., \& Yaure, R. C. (1988). Random access of component skills in acquisition and problem solving. Paper presented at annual meeting of the Psychonomic Society, Chicago, IL.

Cross, E. S., Schmitt, P. J., \& Grafton, S. T. (2007). Neural substrates of contextual interference during motor learning support a model of active preparation. Journal of Cognitive Neuroscience, 19, 1854-1871. http:// dx.doi.org/10.1162/jocn.2007.19.11.1854

Denis, D., Rowe, R., Williams, A. M., \& Milne, E. (2016). The role of cortical sensorimotor oscillations in action anticipation. Neurolmage. Advance online publication.

Ericsson, K. A., \& Kintsch, W. (1995). Long-term working memory. Psychological Review, 102, 211-245. http://dx.doi.org/10.1037/0033295X.102.2.211

Goh, H. T., Gordon, J., Sullivan, K. J., \& Winstein, C. J. (2014). Evaluation of attentional demands during motor learning: Validity of a dual-task probe paradigm. Journal of Motor Behavior, 46, 95-105. http://dx.doi .org/10.1080/00222895.2013.868337

Goode, S., \& Magill, R. A. (1986). Contextual interference effects in learning three badminton serves. Research Quarterly for Exercise and Sport, 57, 308-314. http://dx.doi.org/10.1080/02701367.1986 .10608091

Hall, K. G., Domingues, D. A., \& Cavazos, R. (1994). Contextual interference effects with skilled baseball players. Perceptual and Motor Skills, 78, 835-841. http://dx.doi.org/10.2466/pms.1994.78.3.835

Helsdingen, A., van Gog, T., \& van Merriënboer, J. (2011a). The effects of practice schedule and critical thinking prompts on learning and transfer of a complex judgment task. Journal of Educational Psychology, 103, 383-398. http://dx.doi.org/10.1037/a0022370

Helsdingen, A., van Gog, T., \& van Merriënboer, J. (2011b). The effects of practice schedule on learning a complex judgment task. Learning and Instruction, 21, 126-136. http://dx.doi.org/10.1016/j.learninstruc.2009 .12 .001

Holroyd, C. B., Yeung, N., Coles, M. G. H., \& Cohen, J. D. (2005). A mechanism for error detection in speeded response time tasks. Journal of Experimental Psychology: General, 134, 163-191. http://dx.doi.org/10 $.1037 / 0096-3445.134 .2 .163$

Kahneman, D. (1973). Attention and effort. Englewood Cliffs, NJ: Prentice Hall.

Kane, M. J., \& Engle, R. W. (2003). Working-memory capacity and the control of attention: The contributions of goal neglect, response competition, and task set to Stroop interference. Journal of Experimental Psychology: General, 132, 47-70. http://dx.doi.org/10.1037/0096-3445 .132.1.47

Kilner, J. M., Vargas, C., Duval, S., Blakemore, S. J., \& Sirigu, A. (2004). Motor activation prior to observation of a predicted movement. Nature Neuroscience, 7, 1299-1301. http://dx.doi.org/10.1038/nn1355
Koehn, J. D., Dickinson, J., \& Goodman, D. (2008). Cognitive demands of error processing. Psychological Reports, 102, 532-538. http://dx.doi .org/10.2466/pr0.102.2.532-538

Lam, W. K., Masters, R. S., \& Maxwell, J. P. (2010). Cognitive demands of error processing associated with preparation and execution of a motor skill. Consciousness and Cognition, 19, 1058-1061. http://dx.doi.org/ 10.1016/j.concog.2008.11.005

Lee, T. D. (2012). Contextual interference: Generalizability and limitations. In N. J. Hodges \& A. M. Williams (Eds.), Skill acquisition in sport: Research, theory and practice (pp. 79-93). New York, NY: Routledge.

Lee, T. D., \& Magill, R. A. (1983). The locus of contextual interference in motor-skill acquisition. Journal of Experimental Psychology: Learning, Memory, and Cognition, 9, 730-746. http://dx.doi.org/10.1037/02787393.9.4.730

Lee, T. D., \& Magill, R. A. (1985). Can forgetting facilitate skill acquisition. In D. Goodman, R. B. Wilberg, \& I. M. Franks (Eds.), Differing perspectives in motor learning and control (pp. 3-22). Amsterdam, the Netherlands: Elsevier. http://dx.doi.org/10.1016/S0166-4115(08) $62528-5$

Lee, T. D., Magill, R. A., \& Weeks, D. J. (1985). Influence of practice schedule on testing schema theory predictions in adults. Journal of Motor Behavior, 17, 283-299. http://dx.doi.org/10.1080/00222895.1985 .10735350

Lee, T. D., Swinnen, S. P., \& Serrien, D. J. (1994). Cognitive effort and motor learning. Quest, 46, 328-344.

Lee, T. D., Wishart, L. R., Cunningham, S., \& Carnahan, H. (1997). Modeled timing information during random practice eliminates the contextual interference effect. Research Quarterly for Exercise and Sport, 68, 100-105. http://dx.doi.org/10.1080/02701367.1997 10608871

Lee, T. D., Wulf, G., \& Schmidt, R. A. (1992). Contextual interference in motor learning-Dissociated effects due to the nature of task variations. The Quarterly Journal of Experimental Psychology, 44, 627-644. http:// dx.doi.org/10.1080/14640749208401303

Li, Y., \& Wright, D. L. (2000). An assessment of the attention demands during random- and blocked-practice schedules. The Quarterly Journal of Experimental Psychology, 53, 591-606. http://dx.doi.org/10.1080/ 713755890

Lin, C-H., Fisher, B. E., Winstein, C. J., Wu, A. D., \& Gordon, J. (2008). Contextual interference effect: Elaborative processing or forgettingreconstruction? A post hoc analysis of transcranial magnetic stimulationinduced effects on motor learning. Journal of Motor Behavior, 40, 578-586. http://dx.doi.org/10.3200/JMBR.40.6.578-586

Lin, C. H., Fisher, B. E., Wu, A. D., Ko, Y-A., Lee, L-Y., \& Winstein, C. J. (2009). Neural correlate of the contextual interference effect in motor learning: A kinematic analysis. Journal of Motor Behavior, 41, 232-242. http://dx.doi.org/10.3200/JMBR.41.3.232-242

Lin, C-H., Winstein, C. J., Fisher, B. E., \& Wu, A. D. (2010). Neural correlates of the contextual interference effect in motor learning: A transcranial magnetic stimulation investigation. Journal of Motor Behavior, 42, 223-232. http://dx.doi.org/10.1080/00222895.2010.492720

Long, D. L., \& Prat, C. S. (2002). Working memory and Stroop interference: An individual differences investigation. Memory \& Cognition, 30, 294-301. http://dx.doi.org/10.3758/BF03195290

MacLeod, C. M. (1991). Half a century of research on the Stroop effect: An integrative review. Psychological Bulletin, 109, 163-203. http://dx.doi .org/10.1037/0033-2909.109.2.163

MacLeod, C. M. (1992). The Stroop task: The gold standard of attentional measures. Journal of Experimental Psychology: General, 121, 12-14. http://dx.doi.org/10.1037/0096-3445.121.1.12

Magill, R. A., \& Hall, K. G. (1990). A review of the contextual interference effect in motor skill acquisition. Human Movement Science, 9, 241-289. http://dx.doi.org/10.1016/0167-9457(90)90005-X 
Magnuson, C. E., \& Wright, D. L. (2004). Random practice can facilitate the learning of tasks that have different relative time structures. Research Quarterly for Exercise and Sport, 75, 197-202. http://dx.doi.org/10 .1080/02701367.2004.10609151

Maxwell, J. P., Masters, R. S., Kerr, E., \& Weedon, E. (2001). The implicit benefit of learning without errors. The Quarterly Journal of Experimental Psychology, 54, 1049-1068. http://dx.doi.org/10.1080/713756014

Memmert, D., Hagemann, N., Althoetmar, R., Geppert, S., \& Seiler, D. (2009). Conditions of practice in perceptual skill learning. Research Quarterly for Exercise and Sport, 80, 32-43. http://dx.doi.org/10.5641/ 027013609X13087704027517

Merbah, S., \& Meulemans, T. (2011). Learning a motor skill: Effects of blocked versus random practice a review. Psychologica Belgica, 51, 15-48. http://dx.doi.org/10.5334/pb-51-1-15

Ollis, S., Button, C., \& Fairweather, M. (2005). The influence of professional expertise and task complexity upon the potency of the contextual interference effect. Acta Psychologica, 118, 229-244. http://dx.doi.org/ 10.1016/j.actpsy.2004.08.003

Pauwels, L., Swinnen, S. P., \& Beets, I. A. M. (2014). Contextual interference in complex bimanual skill learning leads to better skill persistence. PLoS One, 9, e100906. http://dx.doi.org/10.1371/journal .pone.0100906

Rabbitt, P. M. (1966). Errors and error correction in choice-response tasks. Journal of Experimental Psychology, 71, 264-272. http://dx.doi.org/10 $.1037 / \mathrm{h} 0022853$

Rabbitt, P. (1967). Time to detect errors as a function of factors affecting choice-response time. Acta Psychologica, 27, 131-142. http://dx.doi .org/10.1016/0001-6918(67)90053-4

Rendell, M. A., Masters, R. S., Farrow, D., \& Morris, T. (2011). An implicit basis for the retention benefits of random practice. Journal of Motor Behavior, 43, 1-13. http://dx.doi.org/10.1080/00222895.2010 .530304

Salmoni, A. W., Sullivan, J. J., \& Starkes, J. L. (1976). The attentional demands of movement: A critique of the probe technique. Journal of Motor Behavior, 8, 161-169. http://dx.doi.org/10.1080/00222895.1976 .10735068

Shea, J. B., \& Morgan, R. (1979). Contextual interference effects on the acquisition, retention, and transfer of a motor skill. Journal of Experimental Psychology: Human Perception and Performance, 5, 179-187.

Shea, J. B., \& Titzer, R. C. (1993). The influence of reminder trials on contextual interference effects. Journal of Motor Behavior, 25, 264274. http://dx.doi.org/10.1080/00222895.1993.9941647
Shea, J. B., \& Zimny, S. T. (1983). Context effects in memory and learning information. In R. A. Magill (Ed.), Memory and control of action (pp. 345-366). Amsterdam, the Netherlands: Elsevier Science Publishers. http://dx.doi.org/10.1016/S0166-4115(08)61998-6

Shea, J. B., \& Zimny, S. T. (1988). Knowledge incorporation in motor presentation. In O. G. Meijer \& K. Roth (Eds.), Advances in psychology (pp. 289-314). Amsterdam, the Netherlands: Elsevier Science Publishers.

Simon, D. A., \& Bjork, R. A. (2002). Models of performance in learning multisegment movement tasks: Consequences for acquisition, retention, and judgments of learning. Journal of Experimental Psychology: Applied, 8, 222-232. http://dx.doi.org/10.1037/1076-898X.8.4.222

Smith, P. J. K., \& Davies, M. (1995). Applying contextual interference to the Pawlata roll. Journal of Sports Sciences, 13, 455-462. http://dx.doi .org/10.1080/02640419508732262

Wright, D. L. (1991). The role of intertask and intratask processing in acquisition and retention of motor skills. Journal of Motor Behavior, 23 , 139-145. http://dx.doi.org/10.1080/00222895.1991.9942031

Wright, D. L., Li, Y., \& Whitacre, C. (1992). The contribution of elaborative processing to the contextual interference effect. Research Quarterly for Exercise and Sport, 63, 30-37. http://dx.doi.org/10.1080/ 02701367.1992 .10607554

Wright, D. L., Magnuson, C. E., \& Black, C. B. (2005). Programming and reprogramming sequence timing following high and low contextual interference practice. Research Quarterly for Exercise and Sport, 76, 258-266. http://dx.doi.org/10.1080/02701367.2005.10599297

Wright, D. L., Verwey, W., Buchanan, J., Chen, J., Rhee, J., \& Immink, M (2016). Consolidating behavioural and neurophysiologic findings to explain the influence of contextual interference during motor sequence learning. Psychonomic Bulletin \& Review, 23, 1-21. http://dx.doi.org/ 10.3758/s13423-015-0887-3

Wulf, G., McNevin, N., \& Shea, C. H. (2001). The automaticity of complex motor skill learning as a function of attentional focus. The Quarterly Journal of Experimental Psychology, 54, 1143-1154. http:// dx.doi.org/10.1080/713756012

Received October 15, 2015

Revision received November 30, 2016 Accepted December 13, 2016 